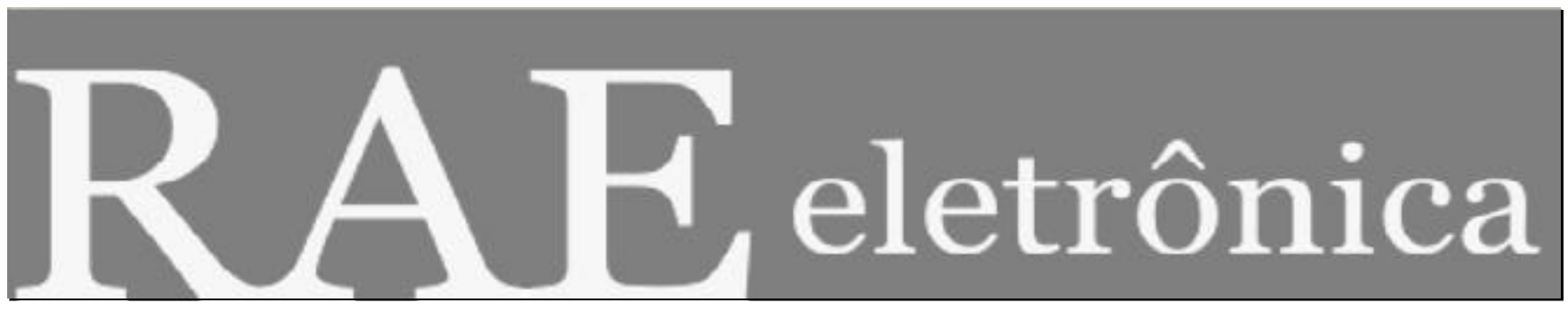

FÓRUM - NOVOS MODELOS ORGANIZACIONAIS: PARADOXOS E CONTRADIÇÕES

ENTRE O DISCURSO E A PRÁTICA

\title{
DO SÓLIDO AO FLUIDO: CONTRADIÇÃO ORGANIZACIONAL E PARADOXO NA RECONSTRUÇÃO DE IDENTIDADE
}

Por:

Djahanchah (Sacha) P. Ghadiri, Judge Business School, University of Cambridge Eduardo Davel, Télé-université, UQAM

RAE-eletrônica, v. 5, n. 1, Art. 9, jan./jun. 2006

http://www.rae.com.br/eletronica/index.cfm?FuseAction=Artigo \&ID=3340\&Secao=Fórum \&Volume= $5 \&$ Numero $=1 \&$ Ano $=2006$

CCopyright, 2006, RAE-eletrônica. Todos os direitos, inclusive de tradução, são reservados. É permitido citar parte de artigos sem autorização prévia desde que seja identificada a fonte. A reprodução total de artigos é proibida. Os artigos só devem ser usados para uso pessoal e nãocomercial. Em caso de dúvidas, consulte a redação: raeredacao@fgvsp.br.

A RAE-eletrônica é a revista on-line da FGV-EAESP, totalmente aberta e criada com o objetivo de agilizar a veiculação de trabalhos inéditos. Lançada em janeiro de 2002, com perfil acadêmico, é dedicada a professores, pesquisadores e estudantes. Para mais informações consulte o site www.rae.com.br/eletronica.

RAE-eletrônica

ISSN 1676-5648

(C2006 Fundação Getulio Vargas - Escola de Administração

de Empresas de São Paulo. 


\section{RESUMO}

Com o objetivo de estimular novos entendimentos acerca de paradoxos e contradições discursivas, a presente pesquisa examina como a identidade é formada e transformada, dentro e ao redor de contextos organizacionais. Desenvolve-se um esquema conceitual em que a identidade é construída e reconstruída a partir da percepção e evocação de imagens, textos, impressões, julgamentos, e situações que expressam algo sobre indivíduos e sobre aqueles com quem esses indivíduos interagem. Tal esquema é ilustrado com base em eventos fictícios, inspirados por um estudo numa empresa do setor moveleiro. De modo geral, esse estudo presume que a identidade nas organizações pode ser melhor compreendida prestando-se mais atenção ao processo de (re)construção de identidade num plano individual e interpessoal de análise. A pesquisa sugere que um melhor entendimento da (re)construção da identidade nesse plano pode contribuir para (a) desafiar a forma como a identidade tem sido (tradicional e teoricamente) abordada nas organizações; (b) iluminar processos de reflexão, regulação e intervenção da identidade de membros organizacionais no dia-a-dia de trabalho, e (c) estimular novos entendimentos sobre a relação que alguns paradoxos comuns e contradições discursivas da vida organizacional têm com a identidade.

\section{PALAVRAS-CHAVE}

Identidade organizacional, paradoxo, contradição discursiva, identidade individual.

\section{ABSTRACT}

In order to stimulate new understandings on paradox and discursive contradictions, this research examines how identity is formed and transformed in and around organization settings. It develops a conceptual scheme in which identity is constructed and reconstructed from perceived and evoked images, texts, affects, judgments and situations expressing something about ourselves and people we interact with. It also provides an illustration of the framework based on fictional events inspired by the study of a company in the furniture sector. Broadly, this examination assumes that identity in organizations can be better understood if we pay more attention to the identity (re)construction process at an individual and interpersonal level of analysis. Our research suggests that a better understanding of identity (re)construction at this level may profitably (a) challenge the way identity in organizations has been (traditionally and theoretically) approached; (b) illuminate processes of identity reflexivity, regulation and intervention by organizational members in everyday life at work and (c) stimulate new understandings on how some common paradox and discursive contradiction, appearing in organizational life, are related to identity.

\section{KEYWORDS}

Organizational identity, paradox, discursive contradiction, individual identity. 


\section{INTRODUÇÃO}

A identidade é um conceito forte, significativo e valioso, dentro e fora das organizações, pois nos remete a definições profundas acerca de pessoas, grupos e organizações; sendo assim, é um construtoraiz em fenômenos organizacionais (Albert, Ashforth e Dutton, 2000). Por ser a identidade crucial no que e como o indivíduo valoriza, pensa, sente e faz em todos os âmbitos sociais (inclusive nas organizações), e por ser um conceito útil ao unir níveis individuais, grupais, profissionais e organizacionais (Kärreman e Alvesson, 2001), é preciso compreender as diversas dinâmicas da identidade.

A identidade se refere a um vasto universo de definições e referências. No campo de estudos organizacionais, ela ora se refere a organizações, ora a indivíduos nas organizações. Se estudada como um Enômeno organizacional, a identidade refere-se genericamente ao que os membros percebem, sentem e pensam sobre suas organizações. De acordo com essa perspectiva, a identidade é considerada como um entendimento coletivo e compartilhado de valores e características distintivos de uma organização (Hatch e Schultz, 1997). A identidade organizacional é normalmente entendida como o conjunto de características centrais, distintivas e duradouras de uma organização (Albert e Whetten, 1985; Dutton e Dukerich, 1991; Brown, 2001; Whetton et al., 1992).

Algumas abordagens sobre a identidade têm se concentrado menos na identidade organizacional do que na formação da identidade individual dentro das organizações. Nesses casos, a identidade se refere a grupos de indivíduos e também a formas de identificação e subjetividade (e.g., Knights e Willmott, 1985, Ashforth e Mael, 1989; Knights e Willmott, 1989; Alvesson e Willmott, 2002; Sveningsson e Alvesson, 2003). Em tais abordagens, a identidade remete a "processos pelos quais as identidades individuais são construídas nas organizações" (Brown, 2001, p. 114). Não nos referimos aqui à identidade como uma essência única e coerente. Ao contrário, consideramos aqui uma identidade que pode ser múltipla e fragmentada, concentrando-nos apenas em identidades desenvolvidas no trabalho e que são formativas de parte do "eu". A identidade é realmente cada vez mais entendida como um processo contínuo de se tornar do que como um objeto sólido ou uma essência (Alvesson e Willmott, 2002; Sveningsson e Alvesson, 2003).

Assim, conceituações da identidade como fluida estão reforçando a crescente literatura em que a solidez de objetos organizacionais é questionada. Ainda que muitos objetos organizacionais, como por exemplo a identidade e a estrutura organizacionais, sejam construídos como sólidos em interações 
diárias, novas perspectivas sobre organizações têm evidenciado cada vez mais a real fluidez desses objetos. Os processos de fluidificação se tornam, portanto, primordiais para a compreensão das tensões entre sólido e fluido nas organizações. Essas tensões se manifestam sobretudo em termos de contradições e paradoxos. Alguns deles estão diretamente relacionados a um importante processo de fluidificação do sólido nas organizações: o processo de reconstrução de identidade.

Neste artigo, propõe-se uma visão proximal dos microprocessos de reconstrução de identidade para uma melhor compreensão de algumas contradições e paradoxos oriundos da tensão entre sólido e fluido nas organizações. A fim de contribuir para tal propósito, o artigo está estruturado da seguinte forma. Primeiramente, desenvolveu-se um modelo que permite captar melhor as sutilezas e complexidades das microdinâmicas da formação de identidade. Posteriormente, ilustram-se tais microdinâmicas por meio de uma narrativa fictícia, inspirada nas atividades de trabalho diárias de uma empresa do setor moveleiro. Finalmente, discutem-se as implicações práticas e teóricas do modelo e da dimensão fluida da reconstrução da identidade, para desenvolver novos entendimentos acerca dos paradoxos e contradições discursivas do trabalho.

\section{RECONSTRUÇÃO DA IDENTIDADE COMO UM PROCESSO FLUIDO: UMA PERSPECTIVA PROXIMAL}

Um vez que a identidade é cada vez mais conceituada como uma noção potencialmente precária e instável (Gioia, Schultz e Corley, 2000), e freqüentemente suscetível a redefinições e revisões pelos membros das organizações, os estudos sobre (re)construção da identidade enquanto processo contínuo têm se tornado crucialmente relevantes (Alvesson e Willmott, 2002; Phillips e Hardy, 1997; Alvesson e Willmott, 2001; Kärreman e Alvesson, 2001; Czarniawska, 2000; Mason e Carr, 2000). Com base em desenvolvimentos teóricos que vêem a identidade mais como uma realização social do que como uma entidade que acontece naturalmente (e.g., Gergen, 1994; Shorter, 1993), considera-se a identidade como o produto constantemente mutante de um processo de reconstrução contínuo, levando-se em conta tudo aquilo que é expresso (contextualmente dito, feito, ou tornado visível), voluntariamente ou não, em relação ao portador da identidade, considerando-se tudo que é evocado por tais expressões.

A definição da identidade como produto derivado de um processo contínuo de reconstrução está associada à noção de narrativa. Sob tal perspectiva, a identidade é um processo contínuo de narração, "em que tanto o narrador como a audiência formulam, editam, aplaudem e refutam vários elementos dessa narrativa constantemente produzida" (Czarniawska-Joerges, 1996, p. 160). Esse processo 
contínuo é assistido por meio da visão proximal do que as organizações se tornam (Cooper e Law, 1995). A partir dessa perspectiva proximal, as organizações e a própria atividade de organizar são compreendidas como um processo continuamente recursivo de interpenetração que parte da visão convencional de organização apoiada em um conjunto de conceitos e categorias estáticos (e.g., estruturas, tecnologia, estratégias).

A (re)construção da identidade nos contextos organizacionais está inscrita em uma dinâmica proximal, considerando que

[...] \& processos organizacionais são fluidos e flexíveis; tudo é móvel e maleável; tudo poderia ser o contrário; tudo está incompleto; tudo é um estado tanto de tensão como de movimento; e se alguns temas forem mais ou menos estáveis por algum momento, isso é, de fato, uma realização então; um resultado alcançado por uma série de traduções reversíveis (Cooper e Law, 1995, p. 264).

Sob essa perspectiva proximal, a identidade nas organizações pode ser proveitosamente compreendida como um processo fluido. Em outras palavras, pode ser concebida como um resultado pontual, parcial, contextual e temporário de um contínuo processo de reconstrução. Argumenta-se que essa reconstrução da identidade se baseia na desestabilização e na reconsideração da identidade em toda interação que envolver novos elementos de expressão, tais como textos, impressões, imagens ou situações. Em outras palavras, a identidade de uma pessoa vai sendo reconstruída cada vez que surgem novas informações ou novos elementos de expressão (vindos da pessoa ou sobre ela).

Por exemplo, cada vez que encontro alguém, tanto a sua identidade como a minha são postas à prova. Serão leve ou profundamente modificadas? O certo é que serão sempre modificadas. Por quê? Porque cada expressão, seja a roupa, a fala, o contexto em que estas se inserem, é uma unidade de um discurso mais amplo, e evoca irremediavelmente imagens, textos, impressões e julgamentos a ela associados (Burr, 1995). Se a identidade for conceituada como um processo fluido, pontual, contextual e temporário, não poderá ser imutável. Sempre será diferente e expressa de forma diferente, pois estará permanentemente sujeita a uma reconsideração com base num fluxo constante de novas informações sobre uma pessoa; é uma escolha contextual de determinados elementos dentro de uma constelação, como se verá mais adiante.

Focando a identidade como um processo contínuo, desenvolve-se e propõe-se um esquema conceitual para o entendimento da formação e transformação da identidade em contextos organizacionais. A partir desse esquema conceitual, considera-se que a identidade é gerada pelo 
confronto com o outro em percepção, por meio de um conjunto percebido de textos, ações, imagens e situações. Tal confronto evocará, ao mobilizar certos discursos, outros conjuntos de imagens, impressões e julgamentos, que constituirão o outro em evocação. Tais conjuntos levarão à reconsideração da identidade do outro, criando o outro em reconstrução. Finalmente, a nova identidade influenciará a percepção e a interpretação do outro em percepção. Todo o processo ocorre em um contexto discursivo, com certos discursos dominantes que são acionados mais facilmente, porém não exclusivamente, para dar sentido a uma pessoa (Sveningsson e Alvesson, 2003).

\section{O outro em percepção}

No primeiro estágio de formação da identidade, o outro é percebido por meio de elementos de expressão, que emergem durante as interações diárias, dentro e ao redor das orga nizações. Durante esse processo, consideramos que qualquer coisa relacionada a alguém e que possa nutrir a formação de sua identidade para outrem assume a forma de textos (o que a pessoa diz ou não, e o que se diz sobre essa pessoa); ações (o que a pessoa faz ou não); imagens (com que a pessoa se parece, sua apresentação física, com que seus objetos se parecem); e situações (em que contexto a pessoa se apresenta e se expressa, ou se é expressa por outrem). A combinação desses elementos toma parte na forma como todos se expressam (por si mesmos ou por outrem). Quando esses elementos são percebidos pelos demais, a definição de quem alguém é se (re)constrói. Essa percepção é influenciada, entre outras coisas, pela identidade prévia daquela pessoa construída até aquele momento, e pelo contexto discursivo em que ocorre a percepção.

Esse processo de percepção do outro pode ser ilustrado pelo exemplo seguinte. Um(a) colega de trabalho, doravante definido(a) como esquerdista, nos conta uma piada racista. Não podemos interpretar essa indelicadeza como prova de racismo pelo que conhecemos dessa pessoa, e devemos levar em conta o que já pensamos a respeito de sua identidade. Em vez disso, podemos perceber e interpretar esse elemento como irônico e, portanto, insignificante. No entanto, o evento modificará sua identidade para nós, pois integraremos esse novo elemento a tudo que evocar a idéia que temos a respeito da pessoa. Isso remete a outro estágio do processo de formação de identidade.

\section{O outro em evocação}

Outro estágio do processo de formação de identidade é a evocação. Ao longo de tal processo, textos, imagens, impressões e julgamentos (ou avaliações) são evocados por qualquer elemento de expressão 
percebido sobre alguém. Esses elementos podem tomar a forma de narrativas, que dão sentido aos elementos de expressão percebidos.

Por textos nos referimos a todos os elementos falados e escritos, ouvidos e lidos, que podem dar significado aos elementos de expressão. São unidades de discursos mais amplos, sendo estes últimos conjuntos de textos inter-relacionados que fazem o objeto tomar forma (Parker, 1992). Por exemplo, se alguém vir uma suástica desenhada no caderno de uma criança, textos sobre a ideologia nazista podem ser evocados para interpretar tal elemento de expressão. Assim, o discurso do nazismo é mobilizado para dar significado ao elemento de expressão.

Outro importante elemento de expressão é a imagem. De acordo com Mitchell (1986), imagens são todas as memórias visuais, gráficas, ópticas e mentais evocadas por um elemento de expressão. Podem ser símbolos, desenhos, fotos, memórias diretas e pinturas, por exemplo. Textos e imagens são mutuamente evocativos e são ambos parte de discursos mais amplos. Se retomarmos o último exemplo, a suástica pode evocar filmes e fotos do Reich, e então fotos dos campos de concentração, fotos de Hitler, lembranças de uma experiência com skinheads, que evocarão textos de violência e intolerância, e que podem evocar outras imagens indiretamente relacionadas a esse símbolo. Estas ajudarão a interpretar o elemento de expressão, porém não necessariamente de maneira correta, pois nesse caso a suástica possui muitos significados diferentes (e.g., na arqueologia persa).

Imagens e textos não estão isolados de outros elementos. Em vez disso, há um relacionamento recíproco entre eles, que se estende para impressões e julgamentos. Por impressões nos referimos a todas as emoções criadas por ou associadas a textos e imagens, e que influenciam as interpretações. Em nosso exemplo, podem ser sentimentos de medo, de desgosto, de raiva e de ansiedade. As emoções também são conduzidas por julgamentos. Os julgamentos são baseados em avaliações sobre dado elemento de expressão, relativas a um quadro moral de referências de alguém (Taylor, 1998). Retornando ao nosso exemplo, o símbolo da suástica pode evocar um julgamento negativo, baseado na avaliação que considera textos associados a esse símbolo com imorais. O quadro moral de referências pode valorizar a democracia, a tolerância e a redução de sofrimento, em oposição ao totalitarismo, ao racismo e à violência.

Quando esse conjunto de textos, imagens, impressões e julgamentos são evocados, podem ser memorizados em um reservatório de traços acerca db outro, que é sempre crescente. Por traços referimo-nos a todos os textos, imagens, impressões e julgamentos que já foram evocados em relação a uma pessoa no passado. Às vezes, serão memorizados de forma narrativa (e.g. uma anedota), que dará sentido particular ao elemento de expressão. 


\section{O outro em (re)construção}

Por meio da percepção e da evocação dos elementos de expressão, constrói-se a definição do outro. Novas impressões e julgamentos associados a esses textos e imagens gerarão uma reconsideração de quem o outro é. Essa reconsideração daquilo em que consiste a identidade do outro pode tomar uma forma explícita ou implícita.

A identidade implícita é formada por uma constelação de textos, imagens, impressões e avaliações prévias (um reservatório de traços do eu), que podem ser acionados (inconscientemente) na interação com uma pessoa. Lidamos aqui com um senso intuitivo e sintético de quem alguém é, baseados em uma seleção de fragmentos de evocações que impressionam a memória até esse ponto.

O que sei sobre alguém é reposicionado em textos, ou ligado a imagens, que são associadas a impressões e julgamentos. Isso me ajuda a interpretar qualquer coisa que a pessoa faça, e que possa se enquadrar em um destes textos ou imagens. A identidade se torna um conjunto de textos, imagens, impressões, e julgamentos que podem ser acionados (inconscientemente) para interpretar elementos de expressão sobre a pessoa.

Por exemplo, se eu souber que alguém é filho único, posso evocar textos (textos científicos, psicologia popular, ficções, dizeres, conversações que tive sobre filhos únicos, ou com filhos únicos), imagens (de pessoas que conheci, de personagens de filmes ou, por exemplo, do pequeno Abdallah, uma personagem das Aventuras de Tintin, uma história em quadrinhos de Hergé), impressões (fascinação, inveja, inimizade, desdém, cumplicidade), julgamentos (egoísta, narcisista, mau, egocêntrico, desprovido de compaixão, independente, teimoso, carismático), ou mesmo experiências que tive com outros filhos únicos. A partir daí, um modelo implícito, composto por es ses traços, pode proporcionar uma interpretação para todas as ações da pessoa.

Por exemplo, posso interpretar que uma ação protagonizada por essa pessoa é egoísta, pois sei que a pessoa é filha única, e o que isso me evoca sugere egoísmo. Mas essa ação pode ser também interpretada como uma ação tipicamente individualista. Textos sobre "individualismo e capitalismo" poderiam ter me ajudado a interpretar os hábitos da pessoa se eu soubesse que ele(a) era um(a) operador(a) de Wall Street.

A outra forma de identidade - identidade explícita - constitui uma integração entre alguns fragmentos ou traços para formar uma definição ou narração parcial, temporária e contextual de quem uma pessoa é, para outrem, num momento preciso. Parcial porque, em uma sentença, a pessoa é incapaz de expressar tudo o que pensa sobre alguém. Temporária porque a identidade pode mudar de um momento a outro, dependendo de novos elementos percebidos sobre o outro. A forma explícita da 
identidade pode ser consistente ou contraditória à identidade prévia. Ademais, a identidade explícita está na intersecção de tudo aquilo que foi evocado, em tudo que foi expresso por ou sobre alguém em um contexto, em uma situação.

Quando a identidade é explícita, sempre é contextual. A definição, ou narração da identidade, dependerá de quem pede essa definição, e em qual contexto. Por exemplo, um(a) policial que nos pergunta quem ele(a) é, invocará uma definição ou narração de identidade diferente da resposta que daríamos analisando um indivíduo atraente do sexo oposto, ou um psicanalista, ou um novo diretor administrativo.

Sob essa perspectiva, podemos falar, portanto, sobre uma infinidade de identidades possíveis, que podem ser acionadas de acordo com a audiência, a situação, o humor da pessoa que tem de definir a outra, o significado que a pessoa pode dar à ação de definição, e a escolha imprevisível entre diferentes traços que (re)emergirão. Uma pessoa possui várias identidades potenciais para um indivíduo, pois esse indivíduo pode criar ou improvisar a sua identidade cada vez que for preciso, de acordo com todos os elementos envolvidos (audiência, situação, e traços lembrados). A identidade explícita é então um processo de improvisação baseado num contexto e numa seleção dos traços de uma constelação. Assim, a identidade pode ser entendida como uma constante e contextual recomposição de um conjunto crescente de traços.

Ambas as formas explícitas e implícitas de identidade são compostas por textos, imagens, impressões e julgamentos. Sua diferença está na forma como são apresentadas à mente. Quando a identidade é implícita, ela é como um sentimento sintético que engloba os fragmentos da evocação. Quando explícita, a definição ou narração do outro está no cruzamento de certos traços (textos, imagens, impressões e julgamentos), acionados de acordo com o contexto, e articulados em um texto explícito. Em suma, a identidade pode ser entendida como a idéia (implícita) ou a definição (narração) (explícita) de quem o outro é, em termos de essência (percebida e reconstruída; quem a pessoa era, é e será), passado (quem a pessoa foi), presente (quem a pessoa é nesse momento) e futuro (quem a pessoa pode se tornar). Essas quatro declinações de identidade é que são reconstruídas a cada vez que novos elementos de expressão aparecem.

Considerar a identidade como uma espiral de processos (percepção, evocação e reconstrução) nos leva a desenvolver uma visão dinâmica de como ela é formada e transformada por meio de atividades e relacionamentos diários, dentro e fora das organizações. A partir daí, a identidade do outro sempre é determinada de acordo com a identidade de quem o percebe. Se alguém mudar profundamente, as impressões e julgamentos da identidade evocados pelo outro também poderão 
mudar. Assim, é também a evolução da identidade de si mesmo que lança a reconsideração e reconstrução da identidade do outro.

Ademais, esse processo completo ocorre em cenários que estão embebidos em um contexto discursivo, e em que alguns discursos são às vezes dominantes. Em cenários organizacionais, alguns discursos são hegemônicos, enquanto outros ocupam uma posição marginal na construção da realidade social. Os discursos são importantes nesse processo de reconstrução de identidade na medida em que são mobilizados em diferentes estágios para orientar percepções, evocações e reconstruções. É, portanto, importante considerar quais são os discursos mobilizados no processo, sejam hegemônicos, marginais ou extra-organizacionais.

\section{Reflexão e intervenção no processo de reconstrução de identidade}

A habilidade de entender e refletir sobre a maneira como a identidade opera nos capacita a exercer certo grau de intervenção no processo de reconstrução da identidade. Nesse sentido, a reflexão leva a uma capacidade de intervenção. Assim, se alguém está ciente de um elemento que possa ser, por exemplo, má influência em sua identidade para os demais, pode substituir esse evento por um discurso que acione textos que evoquem impressões e julgamentos positivos. Pode ainda tentar controlar o quadro utilizado para entender o evento ou elemento.

Por exemplo, numa empresa, durante o expediente, um chefe vê um empregado dormindo no trabalho. Esse empregado terá de substituir esse elemento de percepção por um texto de legitimação. O chefe pode pensar que a pessoa é preguiçosa, usando todos os textos, impressões e julgamentos associados a ela. Nesse caso, o empregado pode dizer "eu trabalhei a noite toda, então tirei um pequeno e revigorante cochilo, para recarregar minhas energias". Com essa sentença, o empregado pode tentar associar o fato de estar dormindo a textos e imagens de dedicação, de trabalho duro, de energia e de vigor, que podem envolver impressões (satisfação) e julgamentos (bom trabalhador) bastante diferentes daquela inicial de preguiçoso.

Ademais, alguém pode influenciar a reconstrução de sua própria identidade por meio da reconstrução da identidade dos demais. Assim, uma pessoa é para os demais uma constelação de textos, imagens, impressões e avaliações que podem ser acionados para regular a identidade da própria pessoa. Se, por exemplo, alguém for agressivo com um indivíduo ou explicitamente julgá-lo negativamente, dizendo que seu trabalho não é profissional, esse indivíduo pode acionar, de seu reservatório de traços sobre a pessoa, uma identidade explícita, que pode atenuar o peso do julgamento feito por ela. Ele pode reconstruir a identidade do outro como antiprofissional, e portanto terá uma opinião irrelevante, para se 
sentir melhor. A idéia é que a reconstrução da identidade depende também da manutenção da avaliação positiva da própria identidade de alguém, ou, em outras palavras, da auto-estima de alguém.

Assim, essa dimensão abre duas possibilidades para a microemancipação (Alvesson e Willmott, 1992): uma ativa e outra passiva. A passiva provém da impossibilidade provinda de relações de poder e necessita ser resolvida de qualquer forma (Knights e Vurdubakis, 1994). A ativa clama por uma tentativa de alguém controlar o processo de reconstrução da própria identidade por parte dos outros, por meio da tomada de responsabilidade ativa pela narrativa de quaisquer elementos de expressão ou eventos aparentemente significantes.

Em outras palavras, prestar atenção na formação da identidade em seus microprocessos tem implicações práticas para a capacidade de os empregados refletirem e intervirem na sua vida organizacional. Claramente, assim como as atividades de atribuir sentido e tomar decisões nas organizações estão intimamente ligadas à identidade (Albert, Ashforth e Dutton, 2000), os gestores e funcionários podem aprimorar sua participação em discursos e em interações diárias com membros da organização, se estiverem aptos a adquirir noções mais refinadas e detalhadas do modo como a identidade se desenvolve. Isso significa que, se os funcionários compreenderem melhor o processo de identidade, poderão aumentar sua consciência das representações realizadas a seu respeito. Baseado na forma como um gestor conversa com uma pessoa sobre ela mesma, como interage com ela, permitindo que faça algumas coisas e não outras, esperando dela algumas coisas e não outras, essa pessoa poderá deduzir o tipo de identidade que o gestor construiu dela. Dessa forma, os funcionários podem tentar influenciar os tipos de elementos que alimentarão a reconstrução da identidade deles no trabalho.

Para os gestores e outros stakeholders organizacionais, como representantes de sindicatos, entender o processo contínuo de formação de identidade é essencial, pois sua principal ferramenta é a fala (Mintzberg, 1973; Chanlat e Bédard, 1990). Conversas gerenciais diárias envolvem conseqüências contínuas e profundas em termos de reconstrução da identidade dos gestores e dos demais. Esse entendimento também pode ajudar a crítica a textos, imagens, impressões e julgamentos que podem surgir quando nos confrontamos com um novo evento que envolva pessoas do trabalho. Pode-se tentar controlar também, até certo ponto, os tipos de textos e imagens (e, portanto, os tipos de impressões e julgamentos) que serão acionados quando confrontados com um novo elemento de expressão no trabalho.

\section{A IDENTIDADE ILUSTRADA POR MEIO DE UMA FICÇÃO ORGANIZACIONAL}


Para aplicar e ilustrar como a identidade é construída e reconstruída por uma espiral de percepção e evocação de elementos de expressão, produzimos uma narrativa fictícia inspirada em um conjunto de eventos organizacionais que ocorreram em uma empresa do setor moveleiro em que um dos autores conduziu um estudo empírico (veja o Quadro 1). O uso da ficção no estudo de processos organizacionais tem sido apoiado principalmente por teorias pós-modernas (e.g., Kilduff e Mehra, 1997; Calas e Smircich, 1999). E por ser a formação da identidade um processo muito sutil, a ficção pode prover um modo útil e acurado de pensar as organizações e identidades. Ademais, também pode iluminar a conexão entre a teoria organizacional e as experiências de participação organizacional (Phillips, 1995). A seguinte narração de eventos na referida empresa se baseia num elemento não fictício: as regras da área de produção impostas pela gestão. 
Quadro 1 - Narrativa fictícia sobre regras organizacionais

Eu acabara de chegar à fábrica. Era o meu primeiro dia de trabalho. Nunca havia visto uma fábrica em minha vida. Imaginava o que seria trabalhar como "peão" numa fábrica. Meu tio era um deles. Trabalhava lá havia 17 anos. Eu o considerava um sujeito determinado e muito prático. Meu pai sempre pedia ajuda a ele quando precisava fazer alguma coisa em casa. Costumava dizer que ele era durão, trabalhador e esperto, qualidades necessárias quando se fala em construção de casas. Ele me impressionava muito, e eu sempre me perguntava se seria como ele. Quando cheguei à fábrica, ainda era um pouco cedo. Vaguei ao redor do prédio até encontrar a entrada da área de produção. Não havia ninguém lá ainda. Para passar o tempo, comecei a ler o quadro de avisos. Não havia muitos, apenas três: dois eramanúncios, um de uma motocicleta e o outro de uma casa de bonecas; o terceiro era uma lista de regras da fábrica. Eis o que li:

"Regras:

-É absolutamente proibido:

- correr sem motivos

- distrair os vizinhos

- atirar objetos sem consideração alguma

- empurrar ou puxar os outros

- brincar com os extintores de incêndio"

Antes que eu pudesse ler mais, ouvi passos atrás de mim. Era meu tio chegando. Senti-me mal e afastei-me do quadro de avisos, como se tivesse feito algo errado. Ele olhou para o quadro, olhou para mim, e disse: "Não se preocupe, essas são regras antigas; nunca as tiramos da parede para nos lembrarmos de como parecíamos imbecis aos olhos da gerência. Pode esquecê-las. Hoje ninguém as leva mais a sério. São apenas brincadeira". E ele continuou sorrindo jocosamente. "Você pode brincar com os ext intores de incêndio se quiser". Ri para ele, mas ainda assim perdi parte de meu entusiasmo para ser um daqueles “peões” e comecei a me perguntar se ficaria muito tempo por ali.

\section{Analisando e identificando a formação da identidade}

A partir do evento, analisaremos a micro-reconstrução da identidade do tio por parte do sobrinho, utilizando o modelo proposto. Quando che ga à fábrica, o sobrinho tem uma definição implícita do que é um trabalhador da área de produção baseado na idéia e na definição que tinha de seu tio. Ao pensar 
no tio, lembra-se de textos (palavras de seu pai sobre ele), imagens (o tio construindo a casa), impressões (fascinação, identificação) e julgamentos (admirável). Estes formam uma constelação de elementos que o sobrinho aciona para interpretar sua própria situação e sua identidade. Ele está no limite da reconstrução da própria identidade sob o modelo de seu tio, como determinado, prático, esperto, trabalhador e durão. Ele também vê o tio positivamente, pois sua identidade como futuro trabalhador do chão de fábrica é elevada pela associação a uma figura forte e positiva.

Ao chegar à fábrica, tudo que descobre é coerente com a identidade que forjou. Ao ler sobre a motocicleta, textos e imagens de virilidade e capacitação mecânica reforçam sua idéia implícita sobre trabalhadores de fábrica e sobre seu tio. No entanto, a casa de bonecas não é congruente com essa identidade para ele, mas evoca textos e imagens de paternidade, e os trabalhadores da área de produção certamente também podem ser pais. Se isso leva a uma pequena reconstrução da identidade deles, ainda assim é coerente com sua idéia sobre eles.

Finalmente, um novo e crucial elemento de expressão associado à identidade dos trabalhadores da área de produção, e portanto a seu tio, e agora a ele mesmo, é introduzido: a lista de regras. Cada regra é percebida e interpretada como um discurso sobre os trabalhadores do chão de fábrica, em determinada situação, considerando as ações específicas a eles atribuídas como possíveis. Cada regra evoca, para o sobrinho, textos (injunções que escutou na escola quando criança), imagens (trabalhadores do chão de fábricas lutando como crianças), impressões (vergonha) e julgamentos (imaturidade, criancice, negatividade).

Isso gera a reconsideração da identidade dos trabalhadores da área de produção, da identidade do tio e de sua própria identidade. Esses novos elementos são interpretados, em oposição às identidades prévias, para determinar a importância da reconstrução. Esses elementos podem ser interpretados como consistentes ou contraditórios. Estão aqui em completa dissonância com a identidade prévia que o sobrinho construíra até aquele instante. Mesmo que ele não o faça explicitamente, a identidade implícita é imediatamente reconstruída. Ela envolve vergonha de seu tio e de si mesmo.

Assim que o tio nota que o sobrinho lera as regras, tenta substituí-las por textos legítimos. Poderia tê-las posicionado com textos sobre segurança, invocando os riscos envolvidos naquele trabalho, ou com textos de exclusão, argumentando que tais textos só se referem a uma minoria ou a um departamento, ou apenas a trabalhadores mais jovens. Ele escolhe posicioná-los em um texto político, invocando o desdém preexistente da gestão e sua representação errônea sobre eles, e também em um texto jocoso, esperando evocar impressões e julgamentos de surpresa e indignação. 
No entanto, não é o suficiente para evitar que o sobrinho evoque impressões (perda de entusiasmo) e julgamentos (perda de orgulho e desdém), reconstruindo a identidade dos trabalhadores da área de produção e a identidade do tio como diferentes da sua: "[...] aquelas pessoas". As identidades essenciais, passadas e presentes são reconstruídas a ponto de ele reconstruir sua própria identidade futura como separada das identidades deles: "Comecei a me perguntar se ficaria muito tempo por ali”.

Nessa ficção, nota-se que o discurso da gestão (lista de regras) envolve textos e imagens de infantilidade, de alienação e de desdém pelos trabalhadores. O que está implícito é que a formação da identidade dos trabalhadores é reconstruída de acordo com os discursos que a gerência possui acerca deles, pela forma como falam com eles, pelas ações que os envolvem, pelas coisas que lhes permitem ou não fazer e dizer, pelas ações e discursos que deles esperam. Em outras palavras, nossa própria identidade também é formada com base em representações que os outros fazem de nós e que carregam em seus discursos e ações relativos a nós. Ademais, oferecemos uma ilustração do fato de que qualquer coisa que se expresse em relação a alguém gera uma reconstrução de sua identidade, seja em continuidade ou em ruptura.

\section{PARADOXO E CONTRADIÇÃO NA RECONSTRUÇÃO DE IDENTIDADES: DA SOLIDIFICAÇÃO À FLUIDIFICAÇÃO}

Propôs-se a conceituação da formação da identidade dentro e ao redor das organizações, enraizada em uma perspectiva organizacional representativa (Cooper e Law, 1995; Weick, 2001; Hosking e Fineman, 1990; Hosking e Morley, 1991) e num entendimento discursivo e processual da identidade (Phillips e Hardy, 1997; Kärreman e Alvesson, 2001; Alvesson, 1994; Hardy, Lawrence e Phillips, 1996; Czarniawska, 1997; Sveningsson e Alvesson, 2003; Alvesson e Willmott, 2002). De acordo com essa perspectiva, em nosso esquema conceitual e na análise de eventos fictícios de uma empresa, a identidade se encontra em movimento por meio de percepção, evocação e reconstrução de elementos de expressão. De fato, sendo dinâmico, esse esquema conceitual sugere várias implicações teóricas e práticas a respeito das organizações, da gestão e da teoria organizacional. Estimula também um novo entendimento sobre a forma como certos paradoxos e contradições organizacionais se relacionam com a identidade.

Em textos organizacionais (como diretrizes, interações diárias, discussões em reuniões cotidianas, planejamento de novos projetos), muitos objetos organizacionais são construídos 
genericamente como muito mais sólidos do que realmente o são. Esses esforços para solidificar tais objetos (concepção de liderança, trabalho em equipe, engajamento de funcionários) são subjugados por processos de fluidificação que permeiam as organizações. O esforço de solidificar realidades diárias fluidas é freqüentemente antiprático e infrutífero.

Ademais, o hia to entre o que gostaríamos de ver como sólido, estável e permanente e o que de fato é líquido, instável e constantemente mutante é uma grande fonte de contradições e de paradoxos nas organizações. Para melhor compreendê-los, precisamos olhar para os microprocessos por meio dos quais o fluido se torna sólido e o sólido se derrete em fluidez Dentre eles, os microprocessos de (re)construção de identidade são centrais. Realmente, a definição da identidade é um grande bloco de construção de visões estáveis sobre os objetos organizacionais e uma das muitas portas pelas quais a mudança e a instabilidade permeiam a rotina cotidiana das organizações.

Além disso, o entendimento da (re)construção da identidade permite maior esclarecimento sobre uma contradição central (entre o que é dito e o que é feito) e um paradoxo (entre o processo de definição da identidade de alguém e do desafio da mesma identidade) que surgem freqüentemente na vida organizacional.

\section{Dizer $=$ fazer?}

Uma contradição relevante em organizações é aquela que se encontra entre um discurso oficial (e às vezes hegemônico), caracterizado por uma estabilidade aparente, por coerência e permeação, de um lado, e, do outro lado, um fluxo de práticas que se torna rapidamente "uma manifestação pervertida daquele discurso". Por "manifestação pervertida do discurso" referimo-nos a um grande desvio do que é considerado e aceito como normal, certo ou apropriado pelo discurso oficial. Por exemplo, podemos encontrar um discurso oficial sobre gestão participativa, democracia e igualdade numa empresa cujas práticas gradualmente promovem e implantam uma cultura real hierárquica e sustentada por um discurso autoritário.Como isso pode acontecer?

Sabemos que os discursos organizacionais oferecem posições ou identidades subjetivas, que funcionam como base e orientação para relações de poder, atitudes, comportamentos e, em última instância, para práticas cotidianas dos membros organizacionais (Knights e Willmott, 1989; Deetz, 1992). A prática e o discurso organizaciona is são normalmente vistos como dois lados de uma mesma moeda. Então, como pode haver contradição entre ambos?

Uma possível razão é que, enquanto o discurso organizacional hegemônico de sustentação da prática parece mais estável e sólido, as identidades se movem permanentemente. Como o esquema 
conceitual indica, as identidades não podem evitar o fato de serem contínua e freqüentemente reconstruídas a cada nova interação pela ação de discursos alternativos, extra-organizacionais e opostos. Noutras palavras, são constituídas em termos de discursos marginais, inclusive o saber local, discursos silenciados, discursos banidos, que sustentam práticas anteriores, e discursos culturais externos (como programas de TV sobre ambientes de trabalho). Sendo assim, conseqüentemente se cria um hiato entre identidades novas e reconstituídas e o discurso organizacional hegemônico. O hiato entre o discurso hegemônico e as identidades cria rupturas nas práticas e nas relações de poder, gerando um estado de contradição entre o que é dito e o que é feito. Como isso acontece? O inevitável movimento das identidades traz uma modificação implícita das relações de poder que podem acarretar um profundo e possivelmente contraditório hiato entre o discurso inicial, que permanece estável e aparentemente predominante, e a realidade do fluxo de práticas (errático ou direcionado por um importante contra-discurso).

Por exemplo, vamos tomar como ilustração a diretoria da empresa que usamos anteriormente. Ela se apresenta à sua equipe como detentora de um estilo de gestão participativo, consistente com o discurso oficial da empresa. A identidade com que ela se apresenta sustentará certo tipo de relação de poder com sua equipe em que ela pode contar com certo teor de confiança e incentivar mais facilmente a mobilização. No entanto, essa identidade da gestão participativa será reavaliada e reconstruída ao longo de suas ações e interações, testemunhadas por sua equipe e pela conversas que tiverem sobre ela. Se, por exemplo, ela mantiver as regras de infantilidade anteriormente apresentadas, estas podem incentivar a reconstrução de sua identidade em termos de um discurso mais autoritário. Essa movimentação de sua identidade também trará uma modificação das relações de poder entre ela e sua equipe: menos confiança e menos mobilização. Isso acarreta práticas cotidianas que, após algum tempo, podem divergir enormemente do tipo de prática que o discurso da gestão participativa deveria sustentar.

\section{Definir identidade $=$ contestar $\mathbf{a}$ identidade $?$}

O paradoxo aparece quando, para estabelecer e solidificar um objeto organizacional, alguém o nomeia e define sua identidade. Nesse ponto, o objeto torna-se algo, e seu significado é estabelecido. Ao mesmo tempo se torna visível e aberto a críticas, questionamentos e reconstruções. O esquema conceitual explica bem a propensão a reconstruir o significado do que parece ser estabelecido. Identificar é solidificar, mas, paradoxalmente, é ao mesmo tempo enfraquecer a solidez e até mesmo acelerar o processo de fluidificação. Por exemplo, a diretora da fábrica, ao definir seu estilo gerencial 
como participativo e ao apresentar sua empresa como familiar e humanista, tenta estabelecer tanto a sua identidade como a da empresa aos olhos de sua equipe. Tão logo o faz, confere existência a dois seres, a diretora participativa e a empresa humanista, que serão continuamente reavaliados em termos dos discursos que foram acionados para construí-los. Cada elemento de expressão sobre ela ou sobre a empresa serve para reavaliar o clamor inicial, e a incongruência mais sutil alimentará a mobilização de discursos alternativos que confiram sentido a ela e à empresa. Em outras palavras, ao apresentar a si mesma e à empresa como humanistas, ele traz uma construção progressiva de identidades alternativas e contraditórias para si e para a empresa.

De maneira similar, a visão da identidade é crucial para o entendimento da identidade organizacional como embebida em reconstruções múltiplas e contínuas. Estas são geradas por fluxos irreversíveis de elementos de expressão e de interpretações correspondentes, que se cristalizam nas formas de narrativa sobre as organizações, compartilhadas em conversas.

Para melhor apreender essa dimensão fluente da qual se levantam paradoxos e reconstruções de identidades organizacionais, o reconhecimento da narração de eventos significativos ou mesmo de detalhes se torna central para as diferentes partes interessadas (stakeholders) dentro e ao redor de uma organização. Isso abre a porta ao uso e abuso de poder na determinação de um significado. No entanto, se nosso modelo aponta para um campo não gerenciado que clama a colonização de diversos interesses, também subestima o triunfo final das forças da mudança emergente. Em outras palavras, nada pode evitar por completo a mudança perpétua das identidades, sejam individuais, coletivas ou organizacionais, e portanto, nada pode evitar que a organização mude sob a aparentemente sólida superfície de imagens, discursos e objetos oficiais.

\section{CONCLUSÕES}

Neste artigo, examinou-se o processo de formação e transformação de identidade. Isso não quer dizer que exploramos o processo de "produção e reconstrução" por completo. Dada a complexidade e variabilidade do conceito de identidade, focamos um ângulo individual e interpessoal de análise, propondo um modelo em que a identidade se constrói e reconstrói a partir da percepção e da evocação de imagens, textos, impressões, julgamentos e situações que expressam algo sobre nós mesmos e sobre as pessoas com quem interagimos.

A partir de nossa abordagem, podemos ver a identidade como uma representação pontual, temporária, parcial e contextual que alguém pode derivar de percepção e evocação. Conseqüentemente, 
a identidade sempre é suscetível à mudança, dado que ninguém pode evitar a produção contínua de novos elementos de expressão, que inevitavelmente geram a construção da identidade. A conceituação dinâmica e mutante de identidade traz muitas contribuições para a pesquisa e para a prática. Teoricamente, nossa discussão sobre a identidade convida os acadêmicos a prestarem muita atenção a uma literatura emergente que coloca os processos de (trans)formação da identidade individual no centro da teoria social e organizacional. Em termos práticos, é importante examinar detalhadamente, no decorrer do tempo, sua produção contextual e pontual, a fim de ilustrar ponderadamente os processos de reflexão, regulação e intervenção da identidade.

Finalmente, propõe-se que este modelo de reconstrução de identidade gere percepções à dinâmica de paradoxos organizacionais, contradições discursivas, identidades organizacio nais, relações de poder e microemancipação Em termos práticos, se esse domínio crucial e sem controle clama pela colonização dos vários stakeholder organizacionais, sua própria natureza escapa ao controle total e à fixação de significado. Assim, representa em última instância um desafio eterno à estabilidade das organizações e, de alguma forma, uma promessa de microemancipação das relações fixas de poder. Esse é talvez o paradoxo máximo, no cerne dos processos de reconstrução de identidade: a propensão humana em preservar um sentido de estabilidade por meio da ordenação de coisas em categorias estáveis é a verdadeira origem da diferença e da mudança nas organizações. Id-entidade, do latim, mesma coisa, é paradoxalmente a panacéia da ordem e a fonte do caos. É por isso que este artigo contribui para entendermos melhor as contradições e paradoxos que surgem da tensão entre a inclinação dos atores organizacionais para solidificar e a fluidez dos fenômenos organizacionais. Solidificar é identificar. Mas como demonstramos, a identidade é um fenômeno bastante fluido. Nossa discussão sobre identidade convida os acadêmicos a prestarem maior atenção a uma literatura emergente, que posiciona processos de (re)construção da identidade individual no centro da teoria social e organizacional. Por exemplo, poderia ser interessante examinar a produção da identidade contextual e pontual com algum detalhamento temporal, para melhor iluminar processos de reflexão, regulação e intervenção de identidade. Aliás, em termos práticos, se este campo não gerenciado e crucial da identidade clama a colonização das várias partes interessadas (stakeholders), sua natureza essencial escapa ao controle total e à fixação de significados. Assim, representa em última instância um desafio eterno à estabilidade das organizações e uma promessa de microemancipação de qualquer forma de fixação das relações de poder. Entender os microprocessos de reconstrução de identidade nos ajuda a entender melhor a contradição entre o que é fixado por meio de discurso oficial e o que surge do fluxo de práticas das pessoas que reconsideram continuamente as identidades umas das outras e a 
forma como se relacionam umas com as outras. Também torna claro o paradoxo entre a fixação de identidades e o engatilhar de sua desestabilização.

\section{REFERÊNCIAS BIBLIOGRÁFICAS}

ALBERT, S.; ASHFORTH, B. E.; DUTTON, J. E. Organizational identity and identification: charting new waters and building new bridges. Academy of Management Review, v. 25, n. 1, p. 13-17, 2000.

ALBERT, S.; WHETTEN, D. A. Organizational identity. In: CUMMINGS, L. L.; STAW, B. M. (Eds.). Research in Organizational Behavior. Greenwich: JAI Press, 1985.

ALVESSON, M. Talking in organizations: managing identity and impressions in an advertising agency. Organization Studies, v. 15, n. 4, p. 535-63, 1994.

ALVESSON, M.; WILLMOTT, H. On the idea of emancipation in management and organization studies. Academy of Management Review, v. 17, n. 3, p. 432-464, 1992.

ALVESSON, M.; WILLMOTT, H. Identity regulation as organizational control: producing the appropriate individual Journal of Management Studies, v. 39, n. 5, p. 619-644, 2001.

BROWN, A. D. Organization studies and identity: towards a research agenda. Human Relations, v. 54, n. 1, p. 113-121, 2001.

BURR, V. An Introduction to Social Constructionism. London: Routledge, 1995.

CALÁS, M. B.; SMIRCICH, L. Past postmodernism? Reflections and tentative directions. Academy of Management Review, v. 24, n. 4, p. 649-671, 1999.

CHANLAT, A.; BÉDARD, R. La gestion, une affaire de parole. In: CHANLAT, J.-F. (Ed.). L'individu dans l'organisation. Québec; Paris: Les Presses de l'Université Laval; Éditions Eska, 1990.

COOPER, R.; LAW, J. Organization: distal and proximal views. Research in theSsociology of Organizations, v. 13, p. 237-274, 1995.

CZARNIAWSKA, B. Narrating the Organization: Dramas of Institutional Identity. Chicago: The University of Chicago Press, 1997.

CZARNIAWSKA, B. Identity lost and identity found? Celebration and lamentation over the postmodern view of identity in social science and fiction. In: SCHULTZ, M.; HATCH, M. J.; 
LARSEN, M. H. (Eds.). The Expressive Organization: Linking Identity, Reputation, and the Corporate Brand. Oxford: Oxford University Press, 2000.

CZARNIAWSKA-JOERGES, B. Autobiographical acts and organizational identities. In: LINSTEAD, S. GRAFTON-SMALL, R.; JEFFCUTT, P. (Eds.). Understanding Management. London: Sage, 1996.

DEETZ, S. Disciplinary power in the modern corporation. In: ALVESSON, M.; WILLMOTT, H. (Eds.). Critical Management Studies. London: Sage, 1992.

DUBAR, C. La crise des identités: l'interprétation d'une mutation Paris: Presses Universitaires de France, 2000.

DUTTON, J. E.; DUKERICH, J. M.; HARQUAIL, C. V. Organizational images and member identification. Administrative Science Quarterly, v. 39, p. 239-263, 1994.

GERGEN, K. J. Realities and Relationships: Souding in Social Construction. Cambridge, MA: Harvard University Press, 1994.

GIOIA, D.; SCHULTZ, M.; CORLEY, K. G. Organizational identity, image, and adaptive instability. Academy of Management Review, v. 25, n. 1, p. 63-81, 2000.

GOFFMAN, E. The Presentation of Self in Everyday Life. New York: Doubleday, 1959.

HARDY, C.; LAWRENCE, T. B.; PHILLIPS, N. Talk and action: conversations and narrative in interorga nizational collaboration. In: GRANT, D.; OSWICK, C. (Eds.). Metaphor and Organizations. London: Sage Publications, 1996.

HATCH, M. J.; SCHULTZ, M. Relations between organizational culture, identity and image. European Journal of Marketing, v. 31, n. 5/6, p. 356-365, 1997.

HOGG, M. A.; TERRY, D. J. Social identity processes in organizational contexts. Philadelphia: Psychology Press, 2001.

HOLMER-NADESAN, M. Organizational identity and space of action. Organization Studies, v. 17, n. 1, p. 49-81, 1996.

HOSKING, D.; FINEMAN, S. Organizing processes. Journal of Management Studies, v. 27, n. 6, p. 583-604, 1990.

HOSKING, D.-M.; MORLEY, I. E. A Social Psychology of Organizing: People, Processes and Contexts. Hertfordshire: Harvester Wheatsheaf, 1991. 
KARREMAN, D.; ALVESSON, M. Making newsmakers: conversational identity at work. Organization Studies, v. 22, n. 1, p. 59-89, 2001.

KILDUFF, M.; MEHRA, A. Postmodernism and organizational research. Academy of Management Review, v. 22, n. 2, p. 453-481, 1997.

KNIGHTS, D.; VURDUBAKIS, T. Foucault, power, resistance and all that. In: JERMIER, J. M. et al. (Eds.). Resistance and Power in Organizations. London: Routledge, 1994.

KNIGHTS, D.; WILLMOTT, H. Power and identity in theory and practice. Sociological Review, vol. 33 , n. 1 , p. 22-46, 1985.

KNIGHTS, D.; WILLMOTT, H. Power and subjectivity at work: from degradation to subjugation. Sociology, v. 23, p. 535-558, 1989.

MASON, E. S.; CARR, A. N. The construction of identity in organizations: beyond the cognitive lens. Current Topics in Management, v. 5, p. 95-116, 2000.

MINTZBERG, H. The Nature of Managerial Work. London: HarperCollins, 1973.

MITCHELL, W. J. Iconology: Image, Text, Ideology. Chicago: The University of Chicago Press, 1986.

PARKER, I. Discourse Dynamics. London: Routledge, 1992.

ROWAN, J.; COOPER, M. The Plural Self: Multiplicity in Everyday Life. London: Sage Publications, 1999.

SHOTTER, J. Conversational Realities: Constructing Life Through Language. London: Sage Publications, 1993.

SVENINGSSON, S.; ALVESSON, M. Managing managerial identities: organizational fragmentation, discourse and identity struggle. Human Relations, v. 56, n. 10, p. 1163-1193, 2003.

TAYLOR, C. Les sources du moi: la formation de Pidentité moderne. Montréal: Éditions du Boréal, 1998.

TSOUKAS, H.; HATCH, M. J. Complex thinking, complex practice: the case for a narrative approach to organizational complexity. Human Relations, v. 54, n. 8, p. 979-1013, 2001.

WEICK, K. E. Making Sense of the Organization. Oxford: Blackwell, 2001.

WHETTEN, D. A.; GODFREY, P. C. Identity in Organizations: Building Theory Through Conversations. Thousand Oaks: Sage Publications, 1998. 


\section{Artigo enviado em 15.04.2004. Aprovado em 14.09.2005.}

\section{Artigo traduzido por Felipe Zambaldi.}

\section{Djahanchah (Sacha) P. Ghadiri}

Doutorando em Administração pela Judge Business School, University of Cambridge, Inglaterra.

Interesses de pesquisa nas áreas de identidade nas organizações, análise de discurso organizacional, arte no ensino da Administração e desenvolvimento organizacional.

E-mail: sacha.ghadiri@ cantab.net

Endereço: 4143, Rivard, Montréal (Québec) H2L 4J1, Canada.

\section{Eduardo Davel}

Professor de Gestão de Pessoas e Comportamento Organizacional na Télé-université, Université du Québec à Montréal. Doutorando em Administração pela HEC Montréal.

Interesses de pesquisa nas áreas de comportamento organizacional, gestão de pessoas e arte no ensino da Administração.

E-mail: edavel@teluq.uquebec.ca

Endereço: Télé- université, UQAM 100, Sherbrooke Ouest, Montréal (Québec) H2X 3P2, Canada. 